\title{
REFORMA E CONTRARREFORMA DA PREVIDÊNCIA SOCIAL NO BRASIL
}

Rosa Maria Marques ${ }^{1}$

Camila Kimie Ugino ${ }^{2}$

\section{RESUMO}

Este texto tem como objetivo analisar os principais pontos da proposta de reforma previdenciária encaminhada pelo executivo em dezembro de 2016. São apresentados e discutidos a idade mínima e o tempo de contribuição mínimo; e o tratamento igual entre rurais e urbanos, homens e mulheres, servidores e trabalhadores do Regime Geral. A análise abrange também as modificações produzidas no projeto quando dos trabalhos da Comissão Mista da Câmara, instalada para discutir a proposta do executivo. A conclusão a que se chega é que o Regime Geral irá diminuir seu nível de cobertura, tendo trabalhadores que não conseguirão preencher os critérios necessários para o acesso à aposentadoria. Também haverá uma redução do valor do benefício médio, dado que dificilmente a grande maioria dos trabalhadores terá como comprovar a contribuição necessária para

1 Professora titular do Departamento de Economia e do Programa de Estudos Pós-graduados em Economia Política da PUC-SP; líder do Grupo de Pesquisa Políticas para o Desenvolvimento Humano (PDH). Foi presidente Sociedade Brasileira de Economia Política (SEP) e da Associação Brasileira de Economia da Saúde (ABrES).

2 Professora do Departamento de Economia da PUC-SP, doutoranda em Ciências Sociais pela PUC-SP e membro do PDH e do Núcleo de Estudos de Ideologia e Lutas Sociais (NEILS). 
obter a aposentadoria de valor pleno. A opção encaminhada deixou de considerar a possibilidade de um novo arranjo social, que não resultasse em aumento do tempo de trabalho ao longo da vida do trabalhador e que ampliasse sua cobertura.

Palavras chave: Reforma da Previdência Social; Aposentadorias; Brasil.

\section{INTRODUÇÃ̃O}

Estamos nos primeiros dias de maio de 2017. Mais uma vez a Previdência Social (PS) brasileira é notícia na mídia televisiva e impressa e nas redes sociais, sendo incontáveis os debates já realizados sobre ela nas universidades, sindicatos, partidos, associaçôes de classe e de bairros, e outras inúmeras formas coletivas de organização. Diferentemente de outros momentos, em que foram propostas mudanças na PS, ela é assunto nos mais diferentes ambientes, de trabalho ao familiar, e constituiu o eixo principal das mobilizaçôes de 8 e 15 de março e da greve geral de 28 de abril. Esta última, envolvendo cerca de 40 milhões de brasileiros, parou diversas atividades em 26 estados e em inúmeras cidades, e foi acompanhada de grandes manifestações e bloqueios de ruas, avenidas e vias de acesso às grandes cidades.

A razão de a proposta de reforma da PS, encaminhada pelo executivo para ser apreciada pela Câmara (PEC 287- A), em dezembro em 2016, estar no centro das atençôes dos brasileiros deve-se a sua radicalidade. Proposta tão abrangente como essa, que altera significativamente a proteção social do risco velhice e morte, em especial, somente pode ser comparada à realizada pela ditadura militar, quando esta unificou os institutos e criou o Instituto Nacional de Previdência Social (INPS), integrante do Sistema Nacional de Previdência Social (SINPAS). Mas, ao contrário daquela, a proposta atual implica aumentar o grau de exclusão (ou diminuir o grau de cobertura em relação ao total de trabalhadores), diminuir o valor do benefício, aumentar expressivamente a idade de início da aposentadoria e de caminhar no sentido da equiparação dos funcionários públicos aos trabalhadores formais do setor privado. Mesmo após as emendas introduzidas no projeto original pela Comissão Especial ${ }^{3}$ e por outras que possam ser adicionadas

Essa comissão foi formada de 37 deputados, sendo seu relator Arthur Oliveira Maia, do Partido Popular Socialista (PPS/BA), partido que compõe a base de apoio do governo Temer. 
na discussão do plenário da Câmara, o Brasil (que se conformará como resultado da aplicação da reforma) será certamente ainda mais desigual e mais excludente do que o atual.

Este texto procura discutir os aspectos centrais da proposta encaminhada e das emendas realizadas pelos deputados no interior da Comissão Especial. Não constitui, portanto, um estudo exaustivo, dado que vários outros itens podem vir a ser objeto de modificação no plenário da Câmara, mas se debruça sobre a base sobre a qual está sendo pensada a Previdência Social brasileira das próximas décadas. O texto está organizado em pontos, começando pela análise de se o projeto amplia ou diminui a exclusão, isto é, se o nível de cobertura em relação à população ocupada é alterado pela possível implantação da proposta encaminhada. $\mathrm{Na}$ segunda parte, discute-se o impacto da reforma sobre o valor da aposentadoria e, na terceira, a proposta de introduzir a idade mínima de 65 anos para todos, igualando, os trabalhadores rurais e urbanos, homens e mulheres, trabalhadores do setor privado e funcionários públicos. Por último, discute-se se a reforma tem como impacto a ampliação da Previdência privada. Em todos esses aspectos, quando possível, apresentam-se as modificações feitas à proposta do executivo pela Comissão Mista da Câmara. Que fique esclarecido que há outros aspectos da reforma que não foram aqui tratados. Optou-se por analisar aqueles mais importantes e que estão sendo objeto da atenção principal da população.

\section{O AUMENTO DA EXCLUSÃO}

A Previdência Social brasileira nunca foi dirigida ao conjunto dos trabalhadores brasileiros. Inicialmente organizada a partir das categorias urbanas dos trabalhadores mais organizados, quando instituída nacionalmente, nos anos 1970, em plena ditadura militar, ampliou sua cobertura a todos os trabalhadores do mercado formal, incluindo, ainda, os jogadores de futebol profissional, os trabalhadores autônomos, a empregada doméstica e o trabalhador rural, além de instituir novos benefícios, tais como o salário família e o salário maternidade. A inclusão dos trabalhadores rurais, cujos benefícios e valores eram limitados, não se equiparando aos urbanos, não foi acompanhada da exigência de prévia contribuição, implicando, portanto, uma ruptura, mesmo que limitada, na lógica meritocrática sob a qual se fundamenta a Previdência Social brasileira (somente tem direito ao (s) benefício (s) aqueles que previamente tiverem contribuído). (BATICHI, 2004). Esse aspecto é interessante de ser salientado porque, em geral, a mídia e os defensores da 
contrarreforma previdenciária associam a não contribuição dos rurais à Constituição de 1988. Na verdade, a origem desse tratamento já estava contemplada quando da criação do INPS. O que os constituintes fizeram foi garantir que os trabalhadores rurais tivessem direito aos mesmos benefícios que os urbanos, isto é, cobertura dos mesmos riscos sociais.

Apesar disso, os trabalhadores informais urbanos e aqueles que, mesmo residindo em zonas rurais, não exerçam atividades ligadas ao campo, nunca foram contemplados pela proteção social derivada da PS. E, como sabido, a proporção dos trabalhadores informais no total dos ocupados nunca foi pequena no Brasil. No auge da expansão recente da formalização do mercado de trabalho, em 2015, quando os níveis de desemprego atingiram as mais baixas taxas de desemprego, 38\% da população ocupada com 15 anos ou mais não contribuía para a PS (PNAD, 2016), localizando-se na informalidade. Com o início da recessão, que provocou o aumento do desemprego para patamares extremamente expressivos $(13,2 \%$, para o trimestre dezembro de 2016 a fevereiro de 2017), certamente a participação da informalidade no total dos ocupados voltou a aumentar.

O nível de exclusão, estruturalmente decorrente da forma de inserção dos trabalhadores prevista na organização da Previdência Social brasileira, na medida em que essa é consubstanciada na contribuição dos empregadores e na dos trabalhadores (descontada dos salários e operacionalmente pagas pelo empregador), tenderia a aumentar caso a proposta de reforma encaminhada pelo governo fosse implantada, isto é, parcela dos trabalhadores do mercado formal não terão condições de se aposentar, pois não terão como preencher uma das condições de acesso prevista, o tempo de contribuição. O tempo mínimo de contribuição incluso no projeto encaminhado passou de 15 para 25 anos (somado à idade de 65 anos). Considerando que a trajetória de parte do trabalhador brasileiro do mercado formal é muitas vezes interrompida pelo desemprego e pela ocupação informal, o cumprimento de 25 anos de contribuição exigirá muito mais tempo para ser comprovado, o que inviabilizará a aposentadoria de muitos. Esse caso é ainda mais agravado para as mulheres, pois, com relação aos homens, são mais sujeitas a ficarem desempregadas e a exercerem atividades precárias (DIEESE, 2017). Por outro lado, há que se considerar que esses trabalhadores também não encontrarão guarida junto à Assistência Social, posto que não preenchem o quesito renda familiar (renda inferior a $25 \%$ do salário mínimo). Esses, portanto, não terão nenhum tipo de cobertura, seja da Previdência ou da Assistência. 
Além disso, a exigência de contribuição dos trabalhadores rurais não assalariados, da economia familiar, implica excluí-los do sistema de proteção, dado que sua renda é incerta e reduzida, não havendo como eles contribuírem regulamente. Quando os constituintes estenderam o direito à aposentadoria aos trabalhadores rurais, de valor igual ao piso de um salário mínimo, sem contrapartida de contribuição, o fizeram por reconhecer a especificidade dessa atividade e com base na experiência internacional. Contudo, no Brasil, ao contrário do que foi feito em outros países, em nenhum momento recursos de impostos foram dirigidos para financiar as aposentadorias dos rurais.

Em 03/05/2017, o texto do relator Arthur Oliveira Maia foi aprovado na Comissão Especial, por 23 a 14. Sobre esse ponto, a proposta original não sofreu alteração.

\section{DA REDUÇÃO DO VALOR DA APOSENTADORIA}

Considerando a proposta enviada pelo executivo, a reforma teria, como segundo impacto, o empobrecimento relativo dos futuros aposentados, dado que foi encaminhado que, aos 25 anos de contribuição e 65 anos de idade, o trabalhador teria direito a somente $51 \%$ do valor médio sobre o qual ele contribuiu e não mais $70 \%{ }^{4}$. Assim, se o trabalhador tiver contribuído sobre 2 salários mínimos, terá direito a pouco mais que 1 salário mínimo, e assim por diante, até o teto de 5 salários mínimos. Caso o trabalhador quisesse receber o equivalente ao salário de contribuição médio sobre o qual contribuiu, teria que trabalhar durante 49 anos - ou começar muito, muito cedo, ou estender, para muito além dos 65 anos, sua aposentadoria. Isto porque, a cada ano além dos 25 anos de contribuição mínimos, seria agregado 1 ponto percentual aos $51 \%$ iniciais.

Nas negociações havidas na Comissão Especial, essa proposta foi modificada, começando, tal como vigora atualmente, com $70 \%$ do salário de contribuição, e foi introduzido um claro incentivo à permanência no trabalho. Assim, a cada ano de trabalho após os 25 anos de contribuição, até completar 30 anos, o valor do benefício é aumentado em 1,5 ponto percentual do salário de contribuição; do trigésimo

4 Atualmente, no Regime Geral, o benefício da aposentadoria por idade é calculado sobre o salário de benefício, aplicando-se o mínimo de $70 \%$ mais 1 ponto percentual por ano de contribuição, limitado a $100 \%$ e ao teto de benefícios. 
primeiro ano até trigésimo quinto, o adicional é de 2 pontos percentuais; e do trigésimo sexto ao quadragésimo, 2,5 pontos percentuais. Dessa forma, depois de quarenta anos de contribuição, o segurado terá direito à aposentadoria de valor igual ao salário sobre o qual contribuiu. Em relação à proposta original, portanto, houve aumento do benefício inicial e redução do número de anos de contribuição exigidos para obter a aposentadoria plena (de 49 para 40 anos).

\section{O AUMENTO DA IDADE MÍNIMA}

A proposta encaminhada pelo executivo considerava a introdução de idade mínima para o segurado se aposentar: de 65 anos, sem distinção entre homens e mulheres; e entre urbanos e rurais; e entre trabalhadores do mercado formal do setor privado e servidores públicos. Isso, somado à exigência de um período mínimo de 25 anos de contribuição (hoje 15 anos), implicava uma grande alteração em relação ao que hoje vigue na Previdência Social. Aqui há três implicações que precisam ser discutidas e um pressuposto: o tratamento igual entre homens e mulheres; o tratamento igual entre urbanos e rurais; o tratamento igual entre trabalhadores do mercado formal do setor privado e os servidores públicos; e, enquanto pressuposto, que é absolutamente necessário introduzir o critério de idade para o acesso à aposentadoria e que essa deva ser de 65 anos. A idade de 65 anos não distinguia, também, categorias de trabalhadores, sendo válida para todos.

Comecemos pela a equiparação entre homem e mulher. Vale lembrar que esse tipo de proposta foi aventado, em diferentes momentos, por integrantes (homens) do Partido dos Trabalhadores, mas nunca se consubstanciou em proposta programática devido à reação encontrada em sua base militante e mesmo entre pesquisadores da área previdenciária. A justificativa era (e ainda é) que as mulheres vivem mais do que os homens e, por isso, permanecem mais tempo no sistema recebendo aposentadoria. E, de fato, as mulheres vivem mais, tal como se pode observar na Tabela 1. Para o ano de 2014, por exemplo, aos 55 anos de idade, enquanto o homem poderia esperar uma sobrevida média de 23,8 anos, a mulher teria uma expectativa de sobrevida média de 27,8 anos, uma diferença de 4 anos. Assim, se essa for aposentada, deve receber por mais tempo o benefício de aposentadoria. Contudo, a mesma tabela mostra que a diferença de anos de sobrevida vai diminuindo na medida em que os anos de vida aumentam. Por exemplo, aos 65 anos de vida, a diferença cai para 3,1 anos. 
Tabela 1 Expectativas de vida em idades exatas e variação em anos no período Brasil - 1940/2014.

\begin{tabular}{|c|c|c|c|c|c|c|c|c|c|}
\hline \multirow{3}{*}{ Idade } & \multicolumn{6}{|c|}{ Expectativas de Vida } & \multirow{2}{*}{\multicolumn{3}{|c|}{$\begin{array}{c}\text { Variação em anos } \\
1940 / 2014\end{array}$}} \\
\hline & \multicolumn{3}{|c|}{1940} & \multicolumn{3}{|c|}{2014} & & & \\
\hline & Total & Homem & Mulher & Total & Homem & Mulher & Total & Homem & Mulher \\
\hline 0 & 45,5 & 42,9 & 48,3 & 75,2 & 71,6 & 78,8 & 29,7 & 28,7 & 30,5 \\
\hline 1 & 52,2 & 49,7 & 54,9 & 75,3 & 71,8 & 78,9 & 23,1 & 22,1 & 24,0 \\
\hline 5 & 52,5 & 49,7 & 55,3 & 71,5 & 67,9 & 75,0 & 19,0 & 18,2 & 19,7 \\
\hline 10 & 48,3 & 45,5 & 51,1 & 66,6 & 63,0 & 70,1 & 18,3 & 17,5 & 19,0 \\
\hline 15 & 43,8 & 41,1 & 46,6 & 61,7 & 58,2 & 65,2 & 17,9 & 17,1 & 18,6 \\
\hline 20 & 39,6 & 36,9 & 42,5 & 57,0 & 53,6 & 60,4 & 17,3 & 16,7 & 17,9 \\
\hline 25 & 36,0 & 33,3 & 38,8 & 52,4 & 49,3 & 55,5 & 16,4 & 16,0 & 16,7 \\
\hline 30 & 32,4 & 29,7 & 35,2 & 47,8 & 44,9 & 50,7 & 15,3 & 15,2 & 15,5 \\
\hline 35 & 29,0 & 26,3 & 31,6 & 43,3 & 40,5 & 46,0 & 14,3 & 14,2 & 14,4 \\
\hline 40 & 25,5 & 23,0 & 28,0 & 38,7 & 36,1 & 41,2 & 13,1 & 13,0 & 13,2 \\
\hline 45 & 22,3 & 19,9 & 24,5 & 34,3 & 31,8 & 36,6 & 12,0 & 11,9 & 12,1 \\
\hline 50 & 19,1 & 16,9 & 21,0 & 30,0 & 27,7 & 32,1 & 10,9 & 10,8 & 11,0 \\
\hline 55 & 16,0 & 14,1 & 17,7 & 25,9 & 23,8 & 27,8 & 9,9 & 9,7 & 10,1 \\
\hline 60 & 13,2 & 11,6 & 14,5 & 22,0 & 20,1 & 23,6 & 8,8 & 8,5 & 9,1 \\
\hline 65 & 10,6 & 9,3 & 11,5 & 18,3 & 16,6 & 19,7 & 7,7 & 7,3 & 8,2 \\
\hline 70 & 8,1 & 7,2 & 8,7 & 14,9 & 13,4 & 16,0 & 6,8 & 6,2 & 7,3 \\
\hline 75 & 6,0 & 5,4 & 6,3 & 11,8 & 10,6 & 12,8 & 5,8 & 5,2 & 6,5 \\
\hline $\begin{array}{c}80 \text { anos } \\
\text { ou }+\end{array}$ & 4,3 & 4,0 & 4,5 & 9,3 & 8,3 & 9,9 & 5,0 & 4,3 & 5,4 \\
\hline
\end{tabular}

Fonte: IBGE

O problema em equiparar as mulheres aos homens, no tratamento da idade mínima para se aposentar, é que se está vendo apenas um dos aspectos que integram a vida de uma mulher: a tendência a serem mais longevas do que os homens. Mas essa ênfase no diferencial de sobrevida das mulheres deixa de considerar a existência de desigualdades de gênero que existem, estruturalmente, no mercado de trabalho e nas relações familiares no Brasil. 
Segundo o IBGE (2016), em 2014, 90,7\% das mulheres ocupadas realizavam afazeres domésticos e de cuidados, para um percentual de apenas $51 \%$ no caso dos homens. Assim, a dupla jornada constitui uma realidade para a grande maioria das mulheres que trabalham. O resultado é que a jornada de trabalho total da mulher é maior do que a do homem, quando somada a realizada enquanto trabalho remunerado com as exercidas no lar (Tabela 2): as mulheres trabalham semanalmente 54, 7 horas e os homens 46,7 horas.

Tabela 2 Jornada de trabalho total.

\begin{tabular}{|l|c|c|c|}
\hline \multicolumn{1}{|c|}{ Gênero } & Produtivo & Reprodutivo & Total \\
\hline Mulheres & 35,5 & 19,2 & 54,7 \\
\hline Homens & 41,6 & 5,1 & 46,7 \\
\hline
\end{tabular}

Fonte: PNAD 2015. Extraído de MUSTAFA et al. (2017).

Se anualizada a diferença de jornada entre mulheres e homens, chega-se a sessenta e seis (66) dias, considerando a jornada padrão de 44 horas semanais. E, como afirma o Departamento Intersindical de Estudos e Estatísticas Econômicas (DIEESE, Op. Cit., p. 4), se extrapolarmos:

(...) esse excedente para o tempo de contribuição à Previdência, significa que, em média, com 25 anos de trabalho, que é o mínimo requerido para elas se aposentarem, as mulheres já teriam cumprido quase 30 anos.

Soma-se a essa realidade da mulher brasileira o fato de ela ganhar menos do que os homens em atividade remunerada. Em 2014, ainda segundo o IBGE, junto ao mercado formal, as mulheres tiveram remuneração menor do que a dos homens em $23,1 \%$. No total das atividades, formais e informais, as mulheres receberam, também em 2014, 30\% menos dos que os homens.

Esses são alguns dos aspectos que ilustram a realidade diferenciada que vivem as mulheres no ambiente de trabalho e familiar. Devido a isso, são incontáveis os pesquisadores que defendem a diferenciação de tratamento entre homens e mulheres, no tocante às condiçôes de acesso à aposentadoria. Exemplo disso, e apenas como um indicativo quase que amostral, é o número expressivo de pesquisadores que se somaram para realizar o estudo "Reformar para excluir" (2017), organizado pela Associação Nacional dos Auditores Fiscais da Receita Federal do Brasil (ANFIP) e pelo Dieese. Foram por essas razões que os constituintes, ao definirem a idade de aposentadoria por idade ou para os rurais, introduziram uma diferença, para menor, de cinco anos no caso das mulheres (BRASIL, 1988, art. 202, parágrafo I). 
Quanto à equiparação entre os rurais e urbanos, a mesma questão aparece: a proposta desconsidera que a realidade das atividades desenvolvidas pela chamada economia familiar ${ }^{5}$ é bastante distinta daquela onde se estabelece claramente a relação entre trabalho assalariados e empregador e quando essas são apoiadas na legislação que regula a jornada de trabalho, entre outros aspectos. Não só as condições de trabalho são outras, muitas vezes envolvendo longas jornadas de trabalho, como a fronteira entre as atividades voltadas para o plantio e para a família apresenta elevado grau de superposição. No caso das mulheres, em particular, isso implica aumento substantivo da jornada de trabalho total em relação às mulheres que trabalham em zonas urbanas.

Antes de se analisar a proposta em si de uma idade mínima de 65 anos, resta mencionar a intenção do governo em não fazer distinção entre o trabalhador do setor privado e o funcionário público em matéria de acesso à aposentadoria, seja ele do governo federal, estadual ou municipal. A rigor, esse movimento, a que chamam de "harmonização" dos regimes, faz parte de uma estratégia maior com relação ao Estado, que vem sendo seguida em vários países (DARDOT e LAVAL, 2016). Trata-se de não reconhecer a especificidade do setor público, introduzindo em seu interior os princípios, objetivos e diretrizes das grandes corporações privadas, no qual o funcionário é tratado de forma igual a de um trabalhador do setor privado, onde impera a lei do mercado, e no qual o equilíbrio das contas é alçado a primeiro objetivo. No Brasil, o seguimento dessa estratégia deu origem à introdução do teto dos gastos do governo federal por 20 anos, mudando o regime fiscal mediante a Emenda Constitucional n. 95/2016.

A introdução de teto para o gasto público não é novidade nos países capitalistas. Contudo, em estudo publicado pelo Fundo Monetário Internacional, que trata das regras fiscais existentes em 89 países, verifica-se que a iniciativa adotada no Brasil não tem paralelo no resto do mundo (BOVA et al., 2015). Em nenhum dos países, que adotam regras que limitam o gasto público, o horizonte temporal é de longo prazo e apresenta condiçôes semelhantes ao que aqui foi aprovado. As práticas adotadas em alguns países ilustram a particularidade da proposta brasileira.

5 Os trabalhadores assalariados do agronegócio não são aqui considerados, devendo contribuir como qualquer outro trabalhador. Trata-se somente dos trabalhadores que exercem suas atividades em regime de economia familiar. 
No caso da Holanda, que limita os gastos desde $1994^{6}$, o teto estabelecido tem uma vigência de quatro anos e inclui as despesas com o pagamento dos juros da dívida pública, que também têm limite fixado. Após a definição dos gastos, aumentos são admitidos, desde que comprovada existência de recursos. Durante 2007 e 2010, em função da crise econômica internacional, o limite para o pagamento dos juros da dívida foi abandonado e, em 2009 e 2010, o mesmo ocorreu no caso de programas assistenciais e seguro desemprego. Na Dinamarca, no mesmo ano que na Holanda, foi limitado o crescimento real do gasto público a $0,5 \%$ ao ano, o que foi elevado a 1\% de 2002 a 2005. Em 2014, no entanto, foram aprovados limites com vigência de quatro anos, aplicados a todas as esferas de governo. Na Suécia, em 1997, foi introduzido um sistema de teto que não permite alterações tal como na Holanda, mas o prazo de vigência é de três anos. Na Finlândia, o prazo é de quatro anos e atinge $75 \%$ do gasto federal. Nesses dois últimos países, não há limite para as despesas com juros da dívida pública. No Japão, desde, 2011, é proibido o aumento dos gastos federais de um ano para o outro. Além desses, outros países tentaram introduzir regras de contenção dos gastos públicos, mas não foram bem-sucedidos. Faltaria ainda mencionar os países que compóem a União Europeia que, de forma geral, limitam o aumento das despesas a percentual igual ao crescimento do PIB e excluem do teto o gasto com o seguro desemprego. De todos os países contemplados pelo estudo, somente os pequenos países da Dinamarca, Geórgia e Cingapura incluem as regras atinentes à expansão do gasto público na constituição. Nos demais, isso é feito mediante leis ordinárias ou de acordos políticos.

Contrastando com essas experiências, o que foi adotado no Brasil, com a EC n. 95/2016, é o congelamento do nível do gasto federal pelo tempo de uma geração, a não inclusão das despesas com os juros da dívida pública e a alteração da constituição. Apesar da destacada desigualdade social e do caráter estrutural da extrema pobreza no país, o que foi aprovado não apresentou qualquer preocupação em resguardar os programas de transferência de renda, tal como o Programa Bolsa Família e o dirigido à população idosa e incapaz (Benefício de Prestação Continua$\mathrm{da}-\mathrm{BPC})$, bem como o seguro desemprego .

6 Em 1985, Reagan aprovou o "Balanced Budget and Emergency Deficit Control Act" que, ao mesmo tempo que aumentava o limite do déficit, criava um plano para que o orçamento ficasse equilibrado em cinco anos. A cada ano, se os objetivos de déficit não fossem atingidos, um processo de cortes automáticos teria lugar: $50 \%$ dos cortes seriam provenientes de gastos discricionários e $50 \%$ da defesa. A Previdência Social, o Medicare, vários programas de combate à pobreza e os juros sobre a dívida estavam isentos desses cortes. Reagan não apoiou o corte da área da defesa.

7 A parte relativa à experiência em outros países beneficiou-se, com algumas alterações, de MARQUES e ANDRADE, 2016. 
Tratar os funcionários públicos de forma igual aos trabalhadores do setor privado implica, como dito anteriormente, não reconhecer a especificidade do Estado. Para o desenvolvimento de suas funçôes, traduzidas em atividades, programas e políticas, faz-se necessária a existência de uma burocracia (no sentido weberiano do termo) que, protegida das pressões de grupos particulares e das conturbações decorrentes de crises econômicas e políticas, seja instrumento efetivo da continuidade das funções do Estado. Daí decorre a introdução de seu tratamento diferenciado quanto à estabilidade no emprego e quanto à renda. Um e outro, no entanto, estão sendo questionados nos países em que a "racionalidade" do mercado está sendo transposta para o aparelho de Estado.

Como reação às manifestações ocorridas em 15 de março, em todo o Brasil e contra a reforma da Previdência, o governo retirou da proposta os servidores dos Estados e Municípios. Essa iniciativa, no lugar de sinalizar um recuo, objetivou dividir o movimento de resistência, posto que os funcionários de muitos estados brasileiros, bem como de grandes municípios, foram essenciais na determinação maciça dos movimentos de 15 de março. Além disso, é preciso se considerar dois aspectos: a) o fato de terem sido retirados da proposta não implica que seu conteúdo não seja reapresentado num segundo momento; b) os estados insolventes, que tenham ou não renegociado suas dívidas junto à União, bem como grandes municípios, que contemplem regimes próprios de Previdência Social, irão implantar ajustes similares aos previstos na proposta do governo federal.

Quanto à introdução do mínimo de $\mathbf{6 5}$ anos para aqueles que ingressarem depois da publicado a Emenda Constitucional relativa à Previdência Social ou que não preencham os critérios de enquadramento na regra de transição, a proposta do governo eleva significativamente o tempo de permanência na vida ativa em relação ao vigente atualmente. Em outras palavras, ela aumenta a jornada de trabalho do trabalhador, quando pensada em termos de sua vida, dividida em atividade e inatividade. Segundo dados do próprio Ministério da Previdência Social, em 2014, a idade média dos que requereram aposentadoria no meio urbano era de 54,2 anos, sendo 52,3 anos no caso das mulheres e de 55,1 anos no caso dos homens (MARQUES e UGINO, 2016). Essas informações dão uma boa dimensão das consequências, em termos de jornada de trabalho da vida, da introdução da idade mínima de 65 anos para o acesso à aposentadoria.

$\mathrm{Na}$ defesa de sua introdução, grande parte da mídia televisiva, impressa e digital, bem como representantes do governo, tem insistido que no Brasil não há critério de idade para a aposentadoria e que os únicos países que não a adotam, além do Brasil, são Irã, o Iraque e o Equador. E isso é uma inverdade. No Brasil, 
desde 1999, mediante a Lei 9.876, fruto da reforma encaminhada por Fernando Henrique Cardoso (FHC), a idade foi introduzida de forma indireta no cálculo do benefício da aposentadoria. Isto é, se a idade não é um critério de acesso à aposentadoria dos trabalhadores urbanos, o é para o cálculo de seu benefício, pois quanto maior a expectativa de sobrevida no momento da aposentadoria, menor será o valor de seu benefício, o que decorre da aplicação do chamado fator previdenciário. Como sabido, embora o critério de idade não tenha sido aprovado pelo Congresso quando da reforma previdenciária encaminhada por FHC, ela "reapareceu", de forma indireta, quando da regulamentação do cálculo do valor da aposentadoria, em consonância ao que estava sendo exigido pelo Fundo Monetário Internacional quando da negociação da dívida externa brasileira (UGINO e MARQUES, 2012).

Além disso, em 11/2015, ainda no governo Dilma, foi aprovada a Lei 13.183, que permite ao segurado escolher, para o cálculo do valor de sua aposentadoria, entre a aplicação do fator e a chamada fórmula 85/95. Essa fórmula combina, ao tempo de contribuição anteriormente exigido para o acesso ao valor máximo do benefício, uma idade (30 e 55, para mulheres; 35 e 60 para homens, respectivamente). Assim, o critério da idade passou a ser explicitado. Em geral, a aplicação dessa fórmula é mais favorável ao segurado do que o fator. Isso não significa, entretanto, que a fórmula 85/95 não considere o envelhecimento da população. Nela está previsto que, a partir de 2019, com vigência por dois anos, seja aumentada em um ano a idade tanto para homem como para mulher, e assim sucessivamente.

Não é possível se analisar o impacto da Lei n. 13.183 sob a idade média dos aposentados, não só porque a mudança é recente, como pelo fato de muitos segurados terem antecipado sua aposentadoria frente ao encaminhamento da proposta encaminhada pelo governo Temer. Mas, no caso do fator, ele provocou o adiamento da entrada de solicitação da aposentadoria, de modo que aumentou a idade média do segurado urbano no momento da aposentadoria. Se, em 1995, ela era de 50,9 anos, essa passou para 54,2 anos, em 2014. Entre as mulheres, no período, chama atenção a queda registrada na faixa de 45 a 49 anos, de $34 \%$ para $23 \%$ e, consequentemente, o aumento nas duas faixas seguintes, de $26 \%$ para $44 \%$ na de 50 a 54 anos e de $16 \%$ para $28 \%$ na faixa de 55 a 59 anos. Entre os homens, destaca-se a redução de $28 \%$ para $10 \%$ na faixa de 45 a 49 anos, e o aumento de $19 \%$ para 37\% na faixa de 55 a 59 anos e de $9 \%$ para $17 \%$ na de 60 a 64 anos. (Tabela 3). (MINISTÉRIO DA PREVIDÊNCIA SOCIAL, 2016). Assim, a adoção da idade, de forma indireta, no cálculo do valor do benefício, já havia aumentado significativamente a permanência na atividade dos segurados da Previdência Social. Nada comparável, contudo, ao que foi proposto pelo governo Temer. 
Tabela 3 Distribuição das aposentadorias urbanas concedidas por faixa etária.

\begin{tabular}{|c|c|c|c|c|c|}
\hline & & 1995 & 1998 & 2008 & 2014 \\
\hline \multirow{7}{*}{ 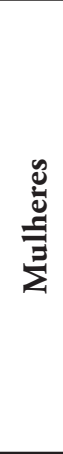 } & 35 a 44 anos & $20 \%$ & $27 \%$ & $3 \%$ & $3 \%$ \\
\hline & 45 a 49 Anos & $34 \%$ & $33 \%$ & $32 \%$ & $23 \%$ \\
\hline & 50 a 54 Anos & $26 \%$ & $23 \%$ & $41 \%$ & $44 \%$ \\
\hline & 55 a 59 Anos & $16 \%$ & $15 \%$ & $22 \%$ & $28 \%$ \\
\hline & 60 a 64 Anos & $3 \%$ & $2 \%$ & $1 \%$ & $2 \%$ \\
\hline & 65 anos e mais & $1 \%$ & $0 \%$ & $0 \%$ & $0 \%$ \\
\hline & Idade média & 49,4 & 48,5 & 51,3 & 52,3 \\
\hline \multirow{7}{*}{ 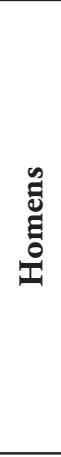 } & 35 a 44 anos & $12 \%$ & $20 \%$ & $4 \%$ & $2 \%$ \\
\hline & 45 a 49 Anos & $28 \%$ & $29 \%$ & $13 \%$ & $10 \%$ \\
\hline & 50 a 54 Anos & $32 \%$ & $26 \%$ & $38 \%$ & $34 \%$ \\
\hline & 55 a 59 Anos & $19 \%$ & $16 \%$ & $32 \%$ & $37 \%$ \\
\hline & 60 a 64 Anos & $9 \%$ & $8 \%$ & $13 \%$ & $17 \%$ \\
\hline & 65 anos e mais & $1 \%$ & $1 \%$ & $1 \%$ & $1 \%$ \\
\hline & Idade média & 51,3 & 50,1 & 53,9 & 55,1 \\
\hline \multirow{7}{*}{ సేّ } & 35 a 44 anos & $14 \%$ & $22 \%$ & $3 \%$ & $2 \%$ \\
\hline & 45 a 49 Anos & $29 \%$ & $30 \%$ & $19 \%$ & $14 \%$ \\
\hline & 50 a 54 Anos & $31 \%$ & $25 \%$ & $39 \%$ & $37 \%$ \\
\hline & 55 a 59 Anos & $18 \%$ & $16 \%$ & $29 \%$ & $34 \%$ \\
\hline & 60 a 64 Anos & $7 \%$ & $7 \%$ & $9 \%$ & $12 \%$ \\
\hline & 65 anos e mais & $1 \%$ & $1 \%$ & $0 \%$ & $1 \%$ \\
\hline & Idade média & 50,9 & 49,7 & 53,1 & 54,2 \\
\hline
\end{tabular}

Fonte: Ministério da Previdência Social, 2016. Elaboração própria.

A proposta do governo previa que a regra de transição seria aplicada aos homens com idade superior a 50 anos e às mulheres com idade superior a 45 anos. Essa regra consistia de um pedágio de $50 \%$ sobre o tempo de contribuição que faltasse para se aposentar, considerada a regra vigente ainda. Ao fim, como resultado dos trabalhos da Comissão Mista da Câmara, foi proposta outra regra de transição, mais amena, tal como se pode acompanhar na Tabela 4. O resultado do que a Comissão Mista estava propondo seria o alongamento do tempo de adoção da idade de 65 anos, com 
aplicação somente para os homens. No caso das mulheres, a idade mínima seria de 62 anos. Tanta uma como a outra teria vigência somente em 2038, isto é, daqui a 21 anos. Para 2019, a idade mínima exigida passaria a 55 anos (homens) e 53 anos (mulheres). Comparado à realidade de 2014, relativa à idade no momento da solicitação da aposentadoria (Tabela 3), o impacto, medido como capacidade de represar a demanda por aposentadoria e de reduzir o valor da mesma, seria bem menor do que se fosse aplicada a regra de transição proposta pelo governo.

Tabela 4 Regra de Transição, Regime Geral, proposta pela Comissão Mista.

\begin{tabular}{|c|c|c|}
\hline \multirow[b]{2}{*}{ Ano } & \multicolumn{2}{|c|}{ Idade Mínima } \\
\hline & Homem & Mulher \\
\hline Até 2019 & 55 anos & 53 anos \\
\hline 2020 a 2021 & 56 anos & 53 anos e 11 meses \\
\hline 2022 a 2023 & 57 anos & 54 anos e 10 meses \\
\hline 2024 a 2025 & 58 anos & 55 anos e 9 meses \\
\hline 2026 a 2017 & 59 anos & 56 anos e 8 meses \\
\hline 2028 a 2029 & 60 anos & 57 anos e 7 meses \\
\hline 2030 a 2031 & 61 anos & 58 anos e 6 meses \\
\hline 2032 a 2033 & 62 anos & 59 anos e 5 meses \\
\hline 2034 a 2035 & 63 anos & 60 anos e 4 meses \\
\hline 2036 a 2037 & 64 anos & 61 anos e 3 meses \\
\hline A partir de 2038 & 65 anos & 62 anos \\
\hline
\end{tabular}

Fonte: Estado de São Paulo, 19/04/2017.

Já para os servidores públicos, a regra de transição proposta pela Comissão Mista é mais dura. Isso porque atualmente já é exigido do servidor público federal uma idade mínima, de 60 anos e 55 anos, para homens e mulheres, respectivamente, fruto da reforma proposta por Luiz Inácio Lula da Silva em 2003 (EC n. 41). Assim, para os servidores homens, a exigência de 65 anos de idade mínima se aplica a partir de 2028, dez anos antes que os trabalhadores segurados pelo Regime Geral da Previdência Social. Já para as servidoras, a exigência de 62 anos ocorrerá a partir de 2036, dois anos antes do que as trabalhadoras do setor privado.

$\mathrm{O}$ argumento para a introdução de uma idade mínima, como critério de acesso à aposentadoria, funda-se no fato de a população brasileira estar vivendo mais. $\mathrm{E}$, como visto na Tabela 1 , isso decorre da evolução demográfica brasileira. $\mathrm{O}$ aumento da expectativa de vida ao nascer e da sobrevida daqueles que se aposentam faz parte de tendência observada no mundo. 
Tabela 5 Regra de Transição, servidor federal, proposta pela Comissão Mista.

\begin{tabular}{|c|c|c|}
\hline \multirow[b]{2}{*}{ Ano } & \multicolumn{2}{|c|}{ Idade Mínima } \\
\hline & Homem & Mulher \\
\hline Até 2019 & 60 anos & 55 anos \\
\hline 2020 a 2021 & 61 anos & 55 anos e 10 meses \\
\hline 2022 a 2023 & 62 anos & 56 anos e 8 meses \\
\hline 2024 a 2025 & 63 anos & 57 anos e 6 meses \\
\hline 2026 a 2017 & 64 anos & 58 anos e 4 meses \\
\hline 2028 a 2029 & 65 anos & 59 anos e 2 meses \\
\hline 2030 a 2031 & 65 anos & 60 anos \\
\hline 2032 a 2033 & 65 anos & 60 anos e 10 meses \\
\hline 2034 a 2035 & 65 anos & 61 anos e 8 meses \\
\hline A partir de 2036 & 65 anos & 62 anos \\
\hline
\end{tabular}

Fonte: Estado de São Paulo, 19/04/2017.

$\mathrm{Na}$ Tabela 6, pode-se observar a expectativa de vida ao nascer e a sobrevida aos 60 anos e aos 65 anos, para homens e mulheres, para vários países. Os países estão agrupados conforme está desenhada a Previdência Social, se fundado no trabalho ou não cidadania ou residência, de modo que seu financiamento está estruturado especialmente com base nas contribuições de empregado e empregador, tal como no Brasil, ou em impostos. Além disso, fez-se um esforço de apresentar dados de alguns países da América Latina. Como esperado, a diferença que o Brasil apresenta com relação aos demais países, em termos de expectativa de vida ao nascer, vai se reduzindo à medida que os anos avançam. Por exemplo, no caso das mulheres, essa diferença é de 6,6 anos ao nascer, entre Portugal e Brasil. Aos 65 anos, ela cai para 1 ano e 9 meses.

No caso do Brasil é preciso, ainda, se considerar as diferenças regionais. Os Quadros 1 e 2 apresentam a sobrevida nas regióes Sudeste, Sul e Centro Oeste, e para as regiōes Norte e Nordeste, respectivamente, para algumas idades. Como se pode observar, na medida em que os anos passam, as diferenças de sobrevida diminuem entre as regiōes mais ricas (Sudeste e Centro Oeste) e as mais pobres (Norte e Nordeste).

De qualquer forma, o fato de a população estar vivendo mais e de, simultaneamente, cair o número de filhos por mulher em idade fértil ${ }^{8}$, coloca um problema para

8 No Brasil, segundo o IBGE, a taxa de fecundidade está em 1,72 filho, abaixo do necessário para a reposição da população. A idade fértil é considerada de 15 e 49 anos de idade. 
o financiamento da Previdência Social. Mas para aqueles que consideram os ganhos de expectativa de vida e de sobrevida observados nas últimas décadas, tal como visto na Tabela 1, uma conquista do conjunto da sociedade, é necessário que se estabeleça um "novo pacto" para sua sustentação, buscando novas formas de financiamento, e não adotar, como única solução, o aumento da idade para se aposentar.

Tabela 6 Expectativa de vida ao nascer e sobrevida aos 60 e 65 anos, em diversos países.

\begin{tabular}{|l|c|c|c|c|c|c|c|c|}
\hline \multirow{2}{*}{ Países $^{*}$} & \multicolumn{3}{c|}{$\begin{array}{c}\text { Expectativa vida ao nascer } \\
\text { de vidal }\end{array}$} & \multicolumn{2}{c|}{$\begin{array}{c}\text { Sobrevida } \\
\text { aos 60 anos }\end{array}$} & \multicolumn{3}{c|}{$\begin{array}{c}\text { Sobrevida } \\
\text { aos 65 anos }\end{array}$} \\
\cline { 2 - 9 } & Homem & Mulher & Total & Homem & Mulher & Homem & Mulher & Total \\
\hline Portugal $^{1}$ & 77,3 & 83,6 & & 21,5 & 25,8 & 17,6 & 21,3 & \\
\hline Espanha $^{1}$ & 79,5 & 85,5 & & 22,6 & 27,3 & 18,7 & 22,8 & \\
\hline França $^{1}$ & 78,7 & 85,4 & & 22,9 & 27,8 & 19,1 & 23,4 & \\
\hline Itália $^{1}$ & 79,8 & 84,8 & & 22,6 & 26,6 & 18,5 & 22,1 & \\
\hline Alemanha $^{1}$ & & 83,3 & & 22,0 & 25,4 & 18,2 & 21,2 & \\
\hline Holanda $^{1}$ & 79,3 & 83,0 & & 22,1 & 25,3 & 18,0 & 21,0 & \\
\hline Dinamarca $^{1}$ & 78,1 & 82,1 & & 21,4 & 24,4 & 17,5 & 20,2 & \\
\hline Suécia $^{1}$ & 79,9 & 83,6 & & 22,6 & 25,5 & 18,5 & 21,1 & \\
\hline Noruega $^{1}$ & 79,5 & 83,5 & & 22,4 & 25,4 & 18,3 & 21,0 & \\
\hline Argentina $^{3}$ & - & - & 76,2 & - & - & - & - & 17,4 \\
\hline Chile $^{1}$ & 76,1 & 81,3 & & 20,7 & 24,1 & 16,7 & 19,8 & \\
\hline Uruguai $^{3}$ & - & - & 77,0 & - & - & 17,8 & - & 17,8 \\
\hline Bolívia $^{3}$ & - & - & 67,1 & - & - & 14,9 & - & 14,9 \\
\hline Equador $^{3}$ & & & 76,4 & & & & & 19,6 \\
\hline Brasil $^{2}$ & 71,0 & 78,3 & 74,6 & 19,8 & 23,3 & 16,3 & 19,4 & 18,0 \\
\hline
\end{tabular}

(1) 2012 - estatísticas da OCDE. (2) 2012 - IBGE. http://www.ibge.gov.br/home/estatistica/ populacao/tabuadevida/2012/defaulttab_pdf.shtm. (3) 2010 - Um panorama dos sistemas previdenciários na América Latina e no Caribe - OCDE, Banco Mundial, BID, 2015.

Isso exige a abertura de um processo democrático de discussão que envolva todos os segmentos da sociedade brasileira. Essa seria a oportunidade de desenhar uma Previdência Social que fosse dirigida ao conjunto da população e não somente aos trabalhadores que estão na formalidade, tal como sempre foi feito no Brasil. O que não é possível se conceber é que a ampliação do tempo de vida se traduza em aumento da jornada de trabalho. 


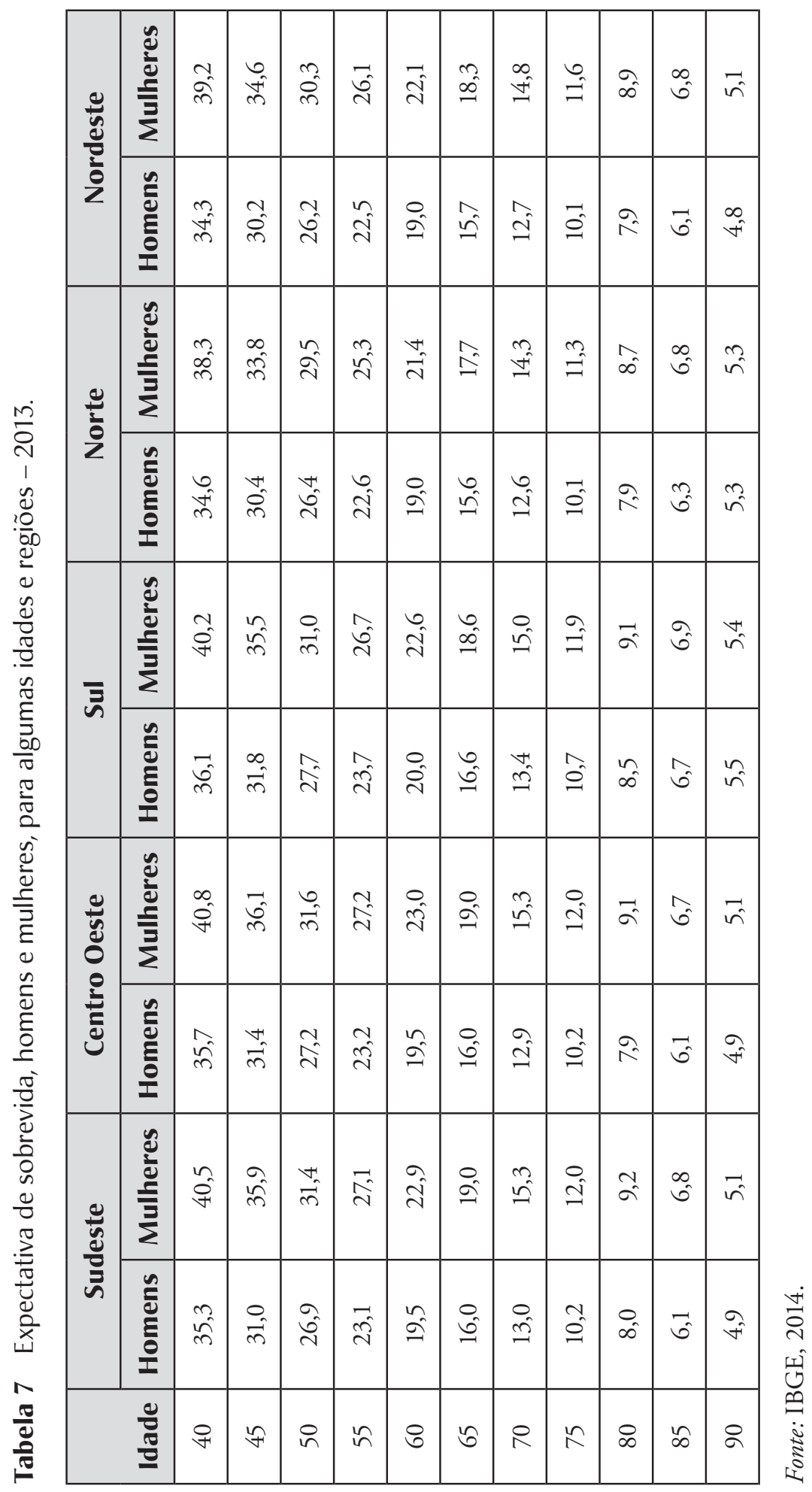




\section{A PREVIDÊNCIA PRIVADA E A REFORMA}

O projeto de reforma do governo Temer não envolve substituir o sistema público de repartição por um privado de capitalização. Há muito ficou claro que essa opção, que foi defendida pelos neoliberais em vários momentos, no Brasil, e proposta pelo Banco Mundial para a América Latina, não era possível de ser aplicada no país. O tamanho do sistema público de proteção social e o número de aposentados sempre se constituíram um obstáculo, dado que o Estado brasileiro não tinha (e não tem) condições financeiras para arcar com o pagamento do estoque de benefícios em caso de privatização.

Mas o que se poderia perguntar é se a aplicação da proposta, tal como foi encaminhada pelo executivo, favoreceria ou incentivaria a ampliação da adesão à Previdência privada, considerando que propunha um benefício que começaria com $51 \%$ do salário médio de contribuição. Em teoria, como dificilmente muitos não teriam condições de contribuir por 49 anos, o valor do benefício tenderia a cair, o que poderia levar a que segurados buscassem complementar sua aposentadoria junto ao setor privado.

No Brasil, a aposentadoria complementar se organiza em fundos de pensão ou entidades fechadas de previdência complementar (EFPC) ${ }^{9}$, e em entidades abertas de previdência complementar (EAPC). A cobertura das entidades fechadas com relação ao total dos segurados do RGPS é muito baixa e se mostra estável nos últimos anos. Contudo, entre aqueles que estão vinculados às entidades fechadas, $75,1 \%$ se concentram nos trabalhadores com renda maior que seis salários mínimos (Tabela 8). Havendo redução do teto do benefício do RGPS, é possível que ocorra um aumento dessa participação.

Tabela 8 Cobertura EFPCs de contribuintes do RGPS - 2011 a 2014.

\begin{tabular}{|l|c|c|c|c|}
\hline & $\mathbf{2 0 1 1}$ & $\mathbf{2 0 1 2}$ & $\mathbf{2 0 1 3}$ & $\mathbf{2 0 1 4}$ \\
\hline Participantes das EFPC / Contrib. empregados do RGPS & $4,6 \%$ & $4,4 \%$ & $4,4 \%$ & $4,5 \%$ \\
\hline $\begin{array}{l}\text { Participantes das EFPC / Contri. empregados do RGPS > } \\
2 \text { SM }\end{array}$ & $13,1 \%$ & $13,2 \%$ & $12,8 \%$ & $13,3 \%$ \\
\hline $\begin{array}{l}\text { Participantes das EFPC / Contrib. empregados do RGPS } \\
>6 \text { SM }\end{array}$ & $70,2 \%$ & $73,1 \%$ & $72,3 \%$ & $75,1 \%$ \\
\hline
\end{tabular}

Fonte: SPPC-MPS, 2015.

As maiores EFPCs são estatais (Funcef - Caixa Econômica Federal; Previ - Banco do Brasil; Petros - PETROBRAS; e Postalis - Correios), mas as EFPCs privadas são numerosas. Em 
Essa tabela nos evidencia que um dos limites para o crescimento dos fundos de pensão no Brasil é a renda média baixa dos trabalhadores. Foi justamente nos segmentos de maiores rendas (acima de seis salários mínimos) que, além da cobertura ser maior, houve maior crescimento no período. Há uma notória relação entre renda e adesão a um plano de previdência complementar; os trabalhadores com menores rendas não conseguem aderir a um plano privado.

Uma segunda modalidade de previdência complementar é oferecida na forma de seguro e, portanto, regulamentada e fiscalizada pela Susep - Superintendência de Seguros Privados. As chamadas entidades abertas de previdência complementar asseguravam, em junho de 2016, seguro previdenciário para 12,5 milhões de pessoas, segundo dados da Susep (2016). Isso significa que, aproximadamente, $15 \%$ da população economicamente ativa possuem seguro previdenciário. De acordo com a Susep, o segmento de previdência complementar aberta movimentou, em 2015, 1,7\% do PIB. Em termos de ativos, ou seja, considerando a receita do ano e as reservas técnicas, esse segmento detinha 10,6\% PIB, no final de 2015.

A hipótese de que esse segmento se amplie, caso o teto do benefício do RGPS for reduzido, parece estar de acordo com as estratégias das seguradoras. Além de estarem interessadas nos segmentos de renda que podem ter sua aposentadoria afetada pela redução do teto, também estão criando "produtos" para setores de mais baixa renda. É o caso da Brasilprev, uma das maiores deste segmento, que vende um plano com contribuição mensal inicial de $\mathrm{R} \$ 25,00$ ao mês, e que representa $31 \%$ de seus contratos de previdência.

Dessa forma, a ampliação possível da previdência complementar devido à reforma proposta ficaria especialmente restrita aos segmentos de maior renda entre os trabalhadores. Contudo, mesmo com a ampliação do valor inicial para $70 \%$ do salário de contribuição, fruto das negociações realizadas na Comissão Mista, não está descartada a possibilidade de setores de baixa renda aderirem ainda mais a planos como esse da Brasilprev, dado que a defesa da reforma tem centrado em sua insolvabilidade, gerando temores crescentes entre a população.

dezembro de 2014, havia 2.597 fundos de pensão no Brasil, sendo $81 \%$ de natureza privada e $19 \%$, pública. A reforma previdenciária de 2003, instituída pela Emenda Constitucional n. 41, viabilizou a criação do fundo de pensão para os servidores públicos federais, regulamentado, contudo, somente em 2012. 


\section{CONSIDERAÇÕES FINAIS}

A proposta de reforma da Previdência Social irá alterar os parâmetros fundamentais sobre os quais se estrutura a aposentadoria dos trabalhadores do mercado formal de trabalho e dos servidores públicos. Haverá aumento substantivo do tempo de contribuição mínimo exigido (de 15 para 25 anos) e da idade, condições indissociáveis para o acesso à aposentadoria. E estas conclusóes dizem respeito tanto à proposta encaminhada pelo executivo, como àquelas negociada no âmbito da Comissão Mista. Algumas categorias e mesmo os trabalhadores rurais, não tratados neste texto, terão tratamento diferenciado, mas, assim mesmo, terão suas condições de acesso pioradas.

O impacto da implantação será o do aumento da exclusão, isto é, a diminuição do nível de cobertura da Previdência Social e a redução do valor do benefício para aqueles não situados no piso, dado que sua correspondência ao salário mínimo será mantida ${ }^{10}$. Os trabalhadores situados na base da pirâmide do mercado formal serão os mais prejudicados no quesito tempo de contribuição, posto que tendem a ser aqueles que mais sofrem com o desemprego e que muitas vezes exercem atividades na informalidade. Estes estão acompanhados pelas mulheres que, mesmo considerando a adoção de uma idade mínima diferenciada (de 62 anos) não têm reconhecido o fato de exercerem uma dupla jornada e que, em geral, ganham menos do que os homens em sua atividade remunerada. $\mathrm{O}$ outro segmento, que será prejudicado com a reforma, é formado pelos servidores, pois a regra de transição pensada para eles os conduz à idade de 65 anos (homens) e 62 anos (mulheres) em tempo bastante reduzido.

Assim, o reconhecimento de que o brasileiro está vivendo mais (que deveria ser saudado como algo positivo) irá ser traduzido pelo aumento da jornada de trabalho medido ao longo da vida. No lugar de buscar outras formas de financiamento, que fossem fundadas nos processos por onde passa a riqueza do capitalismo contemporâneo e que fossem eleitas a partir de ampla discussão junto à população, optou-se por simplesmente aumentar a idade mínima de aposentadoria. A abertura de uma ampla discussão sobre um novo desenho da Previdência Social brasileira seria uma oportunidade para contemplar todos os trabalhadores em sua proteção e não so-

10 Contudo, se o valor do salário mínimo não acompanhar a inflação, mesmo esses terão sofrerão redução do valor do benefício, mas em termos reais. No caso discutido acima, trata-se de redução pura simples do valor do benefício. 
mente aqueles situados no mercado formal. Dessa maneira, no lugar de estarmos discutindo uma contrarreforma, estaríamos debruçados sobre uma reforma, cujo principal objetivo seria ampliar o nível de cobertura. Mas, como sabido, a proposta do governo não envolve alteração do lado da receita. A única exceção fica por conta do fim da isenção da contribuição nas atividades ligadas à exportação.

\section{REFERÊNCIAS}

ANFIP - Associação Nacional dos Auditores Fiscais da Receita Federal do Brasil - e DIESSE - Departamento Intersindical de Estudos e Estatísticas Econômicas. Previdência: reformar para excluir? Contribuição técnica ao debate sobre a reforma da previdência social brasileira. Brasília, ANFIP/DIEESE, 2017.

BATICHI, Mariana. Previdência do trabalhador: uma trajetória inesperada. São Paulo em Perspectiva, v. 18, n. 3, julho/setembro 2004. São Paulo, Fundação Seade, 2004. Disponível em: <http://www.scielo.br/scielo.php?script=sci_arttext\&pid=S0102-88392004000300004>. Acesso em: 03/05/2017.

BOVA, Elva; et al. Fiscal Rules at a Glance. International Monetary Fund, 2015. Disponível em: <https://www.imf.org/external/datamapper/FiscalRules/Fiscal\%20Rules\%20at\%20 a\%20Glance\%20-\%20Background\%20Paper.pdf>. Acesso em: 13/11/2016.

BRASIL, 1988. Constituição da República Federativa do Brasil. São Paulo, Saraiva, 1988.

DARDOT, Pierre e LAVAL, Christian. A Nova Razão do Mundo. São Paulo, Boitempo, 2016.

DIESSE - Departamento Intersindical de Estudos e Estatísticas Econômicas. As mulheres na mira da Previdência Social. Nota Técnica, n. 171, março de 2017. São Paulo, Dieese, 2017.

IBGE - Instituto Brasileiro de Geografia e Estatística. Tábua completa de mortalidade para o Brasil - 2014. Disponível em: ftp://ftp.ibge.gov.br/Tabuas_Completas_de_ Mortalidade/Tabuas_Completas_de_Mortalidade_2014/notastecnicas.pdf. Acesso em: 08/05/2017.

IBGE - Instituto Brasileiro de Geografia e Estatística. Pesquisa nacional por amostra de domicílios: Sintese de indicadores 2015. IBGE, Coordenação de Trabalho e Rendimento. Rio de Janeiro, IBGE, 2016.

MARQUES, Rosa Maria e ANDRADE, Patrick. Democracia burguesa e dominância do capital portador de juros: apontamentos sobre processos em curso no Brasil. Salvador, $O$ Olho da História, dezembro de 2016. Disponível em: <http://oolhodahistoria.ufba.br/ wp-content/uploads/2016/12/rosamaria-1.pdf >. Acesso em: 08/05/2016.

MINISTÉRIO DA PREVIDÊNCIA SOCIAL. Aeps Infologo. Vários anos. Disponível em: <http://www3.dataprev.gov.br/infologo/>. Acesso em: 28/08/2016. 
-• Economia Brasileira em Debate

MOSTAFA, Joana et al. Gênero, previdência e cuidados. In: SEMINÁRIO REFORMA DA PREVIDÊNCIA: DESAFIOS E AÇÃO SINIDICAL. Apresentações... São Paulo: DIEESE e 16 Centrais Sindicais, 7 e 8 fev. 2017. Grupo de Trabalho do IPEA. Disponível em: http://www.dieese.org.br/evento/seminarioReformaPrevidenciaApresentacao.html. Acesso em: 04/05/2017.

OCDE. Estatísticas. Disponível em: <http://stats.oecd.org/Index.aspx?lang=en \&SubS essionId=0f24e52f-fe74-45e8-ba1b-919fbc358154\& themetreeid=21\#>. Acesso em: $11 / 10 / 2016$.

OCDE; Banco Mundial; BID. Um panorama dos sistemas previdenciários na América Latina e no Caribe. Brasília: BID, 2015. Disponível em: <https://publications.iadb.org/ handle/11319/6892>. Acesso em: 11/10/2016. 2015.

SSPC. Informe da Previdência Complementar 2015. Brasília: Ministério do Trabalho e Previdência Social, 2015. Disponível em: <http://www.previdencia.gov.br/wp-content/ uploads/2016/01/Informe-de-previdencia-complementar-FINAL-3.pdf>. Acesso em: $22 / 11 / 2016$.

SUSEP. Boletins consolidados de seguros, capitalização e previdência privada aberta. Disponível em: <http://www.susep. gov.br/menu/estatisticas-do-mercado/boletinsestatisticos $>$. Acesso em: 21/11/2016.

UGINO, Camila Kimie e MARQUES, Rosa Maria. As reformas previdenciárias brasileiras sob a pressão neoliberal. Textos \& Contextos, v. 11, n. 1, p. 24 - 39, jan./jul. 2012. Porto Alegre, PUCRS. 